Original Article

\title{
Comparison of Low - Versus Medium-Pressure Shunts in Pediatric Hydrocephalus - A Study of the Children Hospitals, Lahore
}

\author{
Mian Awais' ${ }^{1}$, Akhtar Muner', Laeeq-ur-Rehman' ${ }^{1}$, Akmal Hussain ${ }^{2}$, Ihsan Ullah ${ }^{3}$, Lubna ljaz ${ }^{1}$ \\ ${ }^{1}$ Department of Pediatric Neurosurgery, The Children Hospital and The institute of Child Health, Lahore \\ ${ }^{2}$ Department of Neurosurgery, Allied Hospital Faisalabad. ${ }^{3}$ Lady Reading Hospital, Peshawar - Pakistan
}

\section{ABSTRACT}

Objective: This prospective cross-sectional study was aimed to assess the effectiveness of low-pressure vs. medium-pressure shunts in children with hydrocephalus.

Material and Methods: 52children with different types of hydrocephalus were admitted through OPD and Surgical emergency at The Children Hospital, Lahore. All Children were gone through Ultrasonography and CT Brain plain after admission. The pediatric hydrocephalus was resolved into two groups. All patients treated with Chhabra differential pressure VP (ventriculoperitoneal) shunt in either low pressure or medium pressure. $\mathrm{CT}$ scans were used to assess the postoperative clinical and radiological outcomes to monitor the ventricle hemispheric ratio (VHR).

Results: A low-pressure shunt was implanted in 26 individuals, whereas a medium-pressure shunt was implanted in 26 individuals. Patients varied in age from one day to thirteen years old. In group $A$, the average VHR was $57.58 \%$ preoperatively, but it dropped to $42.88 \%$ after surgery. Similarly, in group B, the pre-and postoperative VHR was $59.35 \%$ and $42.81 \%$, respectively, which was statistically significant. In both groups, the incidence of shunt complications and redo shunt operation were not statistically significant.

Conclusion: In this study, individuals with pediatric hydrocephalus who had a low-pressure shunt or a medium-pressure shunt had similar outcomes.

Keywords: Hydrocephalus, Shunt Device Pressures, Ventriculoperitoneal Shunt, ventricle hemispheric ratio (VHR).

\section{Corresponding Author: Mian Awais}

Department of Pediatric Neurosurgery, The Children Hospital and The institute of Child Health, Lahore - Pakistan

Email: mian.awais00@gmail.com

Date of Submission: 25-05-2021

Date of Revision: 20-06-2021

Date of Online Publishing: 30-06-2021

Date of Print: 30-06-2021

DOI: $10.36552 /$ pjns.v25i2.553

\section{INTRODUCTION}

The term "hydrocephalus ex vaccuo" refers to an excessive build-up of cerebrospinal fluid (CSF) within the brain ventricular system produced by a disruption in the generation, flow, or absorption of (CSF). It describes asymptomatic ventricular enlargement produced by a generalized loss of brain parenchyma as a result of severe head trauma, infarction, or cerebral hypoxia. There is no 
consistency of care or treatment between different forms of hydrocephalus and the shunt pressure systems employed among the verified cases of hydrocephalus at our facility. In this current study, we assessed the effectiveness of low-pressure vs medium-pressure shunts in children with hydrocephalus.

Ventriculoperitoneal (VP) shunts are the standard treatment options in children with hydrocephalus, especially in neonates and infants. $^{1-2}$ CSF is diverted from the brain's ventricles into the peritoneal cavity using this sort of shunt. The distal catheter's tip lies in this hollow close, but not within, the intestine and bowel loops. The CSF that has been redirected to this location is reabsorbed into the circulation and expelled through regular urine. In an adult, the usual rate of CSF synthesis is $0.35 \mathrm{ml} / \mathrm{min}$. Normal lateral and third ventricles have a capacity of around $20 \mathrm{ml}$, but an adult's total CSF volume is $120-150 \mathrm{ml}$. As a result, CSF is recycled three times each day under typical circumstances. The valves simply function based on the opening pressure, which is the difference in pressure between them. There are no uniform standards for low pressure $\left(0-5 \mathrm{~cm}\right.$ of $\left.\mathrm{H}_{2} \mathrm{O}\right)$, medium pressure $\left(5-10 \mathrm{~cm}\right.$ of $\left.\mathrm{H}_{2} \mathrm{O}\right)$, and high pressure (10-15 cm of $\mathrm{H}_{2} \mathrm{O}$ ) shunts. Once open, these valves provide very little resistance to flow. Drake et al. in a large-scale randomized trial compared standard differential valves to externally programmable valves and found that the new design did not significantly impact the shunt failures. ${ }^{3-4}$ The selection of low -medium pressure shunts has been a matter of controversy for the last 25 years. There is no well-defined indication for the selection of shunts and their efficacy. Not many studies done on this issue and the few studies that have been done have given equivocal results. $^{5-6}$ We present a comparison on the outcome of low- versus medium-pressure shunts in pediatric patients with hydrocephalus in the largest tertiary care pediatric hospital of Pakistan.

\section{MATERIAL AND METHODS}

\section{Study Design \& Setting}

A prospective cross-sections study was conducted at The Children Hospital and The Institute of Child Health Lahore, Pakistan. A total of 52 patients with pediatric hydrocephalus were admitted, operated and followed up from December 2020 to May 2021. Informed consent was taken from the parents or attendants of the children. Ethical approval from the concerned department was obtained prior to the study.

\section{Patients' Groups \& VP Shunting}

The children with hydrocephalus were randomized to receive low- or medium-pressure VP shunts and were categorized into two groups (group $A=26$ and group $B=26$ patients). Randomization was done by a computergenerated method. Third-person (randomizer) who was not part of the study and, thus, participant, investigator, and analyzer were unaware of group distribution, establishing a triple-blind study. In all children, the Chhabra VP shunt, either low or medium pressure was used. VP shunting was done according to the routinely established procedure through the parietal approach.

\section{Post-operative Assessment \& Follow-Up}

The children were followed up postoperatively on a monthly basis for the first 3 months and then 36-months thereafter. The children were also assessed for any known complications of the shunting procedure, like infections, malfunctions, and seizures. The post-operative assessment was done from radiological evaluation of the ventricular size by measuring the ventricularhemispheric ratio (VHR) pre- and postoperatively (at 3 months). 


\section{Ventricle Hemispheric Ratio (VHR)}

The ventricle hemispheric ratio-VHR (normal: 24$33 \%$ was calculated from the computed tomography (CT) scan films or on ultrasonography by calculating the ratio of the maximum ventricular diameter of the frontal horn of the lateral ventricle at the level of the atrium to the diameter of the brain at the same level.

\section{Statistical Calculations}

All data was calculated in the SPSS version 25 . Normality of the data was assessed by the Shapiro Wilk test. As data was distributed normal, and therefore independent-sample $t$ and paired sample t-tests were applied to compare the preop and post-op Ventricle hemispheric ratio between groups.

\section{RESULTS}

\section{Age Distribution}

The median age of group A was 6 months $(0-36$ years) and of group B was 4 months (0 - 120 years). Infants (79\%) dominated the study; the eldest patient in our study was of 13 years and the youngest was of 15 days.

\section{Management of Shunt Surgery}

26 cases (in group A) had low-pressure shunts, whereas, other 26 patients (in group B) had medium-pressure shunts. Indications for shunt surgery were as follows: the congenital hydrocephalus associated with meningomyelocele $\quad(72 \%)$ congenital hydrocephalus alone (18\%) and others (10\%). The patients with meningomyelocele underwent a meningomyelocele repair at the time of presentation. A VP shunt was placed later when these patients developed increasing head size and VHR. Most male patients were present in both groups (group A 20/26 versus group B $15 / 26)$. The increased head size $(67.5 \%)$ was the common clinical feature, followed by signs of meningitis, raised intracranial pressure, and other neurological signs. The mean follow-up was 23 months (ranging from 12 to 42 months) (Table 1).

Table 1: Age and Gender Distributions.

\begin{tabular}{|lcc|}
\hline \multirow{2}{*}{ Age } & Male Patients & Female Patients \\
& Total: $35(67.30 \%)$ & Total: $17(32.69 \%)$ \\
2 months to 2 years & $28(53.84 \%)$ & $13(25 \%)$ \\
$2-10$ years & $6(11.53 \%)$ & $3(5.7 \%)$ \\
$10-13$ years & $1(1.92 \%)$ & $1(3.8 \%)$ \\
\hline
\end{tabular}

\section{Demographic}

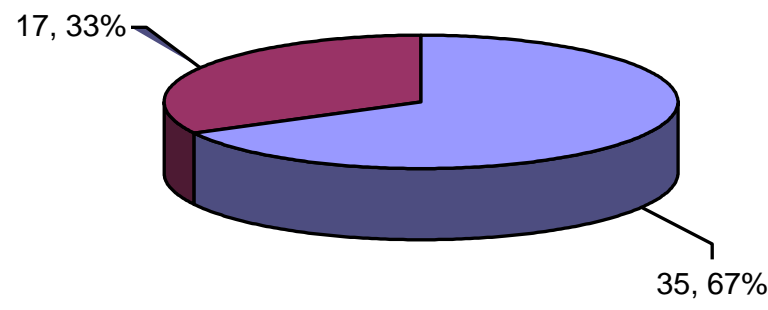

DMales $\quad \square$ Females

Figure 1: Pie-Chart (Male \& Female Distribution).

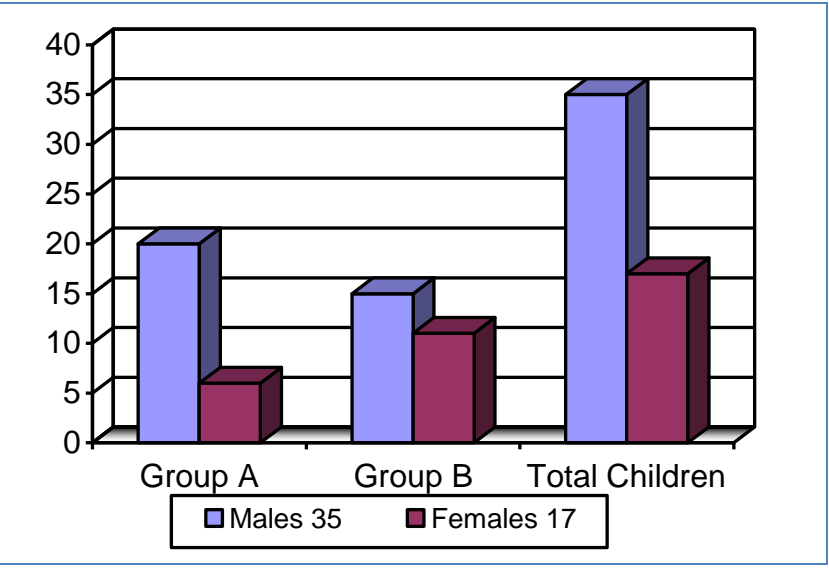

Figure 2: Patients distribution in both groups. 
Table 2: Comparisons of Ventricular Hemispheric Ratios (VHRs) in both Groups.

\begin{tabular}{lcccc} 
Groups & Pre-op VHR & Post-op VHR & \multicolumn{1}{c}{ Change in VHR $^{\text {P-value }}$} \\
Group A: (Low-pressure shunts) & $57.58 \pm 5.75$ & $42.88 \pm 5.16$ & $14.69 \pm 4.08$ & $<0.001^{*}$ \\
Group B: (Medium-pressure shunts) & $59.35 \pm 5.93$ & $42.81 \pm 5.19$ & $16.54 \pm 4.62$ & $<0.001^{*}$ \\
p-value $€$ & 0.280 & 0.957 & 0.133 & -
\end{tabular}

Key: 'Paired sample t test; ${ }^{\boldsymbol{\epsilon}}$ Independent sample t test

\section{Comparisons of Ventricular Hemispheric Ratios (VHRs)}

Results revealed that there was no difference in mean Ventricle hemispheric ratio between both groups preoperatively and postoperatively. The average preoperative VHR in group A was $57.58 \%$ which reduced to $42.88 \%$ postoperatively ( $p<$ 0.001); likewise, the average preoperative VHR in group B was $59.35 \%$ which reduced to $42.81 \%$ postoperatively $(p<0.001)$ and both the differences were statistically significant (Table 2). The mean decrease in VHR in group $A$ was $14.69 \%$ while in group B it was $16.54 \%$ but this difference was statistically insignificant ( $p=$ 0.133).

\section{Complications \& Follow-up}

There was no incidence of slit ventricle syndrome in either group. On follow-up, four patients had shunt blockages (10\%), two in each group, with three patients having associated shunt infections (two patients from the low-pressure group and one patient from the medium-pressure group). One patient in the medium-pressure group developed shunt breakage. Five patients required redo shunt procedure due to these complications (three patients in the low-pressure group and two patients in the medium-pressure group) ( $p=$ 0.5614).

\section{DISCUSSION}

Very few studies have been conducted calculating the VHR of children with hydrocephalus. ${ }^{1}$ McQuarrie et al. in one of his study in adult-onset obstructive hydrocephalus concluded that lowpressure shunts were followed by better (68\%) objective improvement in all the cases than medium-pressure shunts, a similar study was done by Boon et al, in adults with normal pressure hydrocephalus (NPH), ${ }^{5,7-8}$ while Larsson et al, in their study concluded that clinical effect and reduction in ventricular size are independent of shunt opening pressure. ${ }^{9}$ Recent studies have concluded that standard differential pressure valve shunts with the newer anti siphon valves and flow-regulated valves usage. The use of these valves are still in the debate because some authorities take it beneficial and others consider it non-beneficial. ${ }^{2,10-11}$ These valves are very costly then standard valves, so their efficacy are still in debate and they are not freely available in our country. The majority of our patients are not able to afford these shunts.

In the current study, we used the standard Chhabra shunt, which is very cheap and freely available in Pakistan. The Chhabra shunt is a costeffective device that includes a procedure for avoiding gravitational syphoning. In a vertical position, 1 - 3 stainless steel weighing balls (depending on performance level) press on a sapphire ball, closing the CSF flow aperture and raising the shunt's opening pressure. The opening pressure is theoretically equal to $0 \mathrm{~mm} \mathrm{Hg}$ when the balls fall away in the horizontal position. Other gravitational shunts, such as the Cordis horizontal-vertical LP (Lumboperitoneal Shunt) valve, the dual-switch Miethke valve (of Germany), and the Fuji (of Philippines)-a low-cost valve, use the similar principle. $^{12}$ Previous literature did not specify whether to use low- or 
medium-pressure shunts or the indications for either. In another study by Robinson and Park (2001) on 200 patients considered mediumpressure valve perform better than low-pressure valve, and concluded that the valve opening pressure was the only important modulated factor linked with shunt malfunction. Also, the difference in outcome was explained by the fact that a lowpressure valve allows gradually more drainage of cerebrospinal fluid, resulting in smaller ventricles and a higher risk of proximal occlusion. ${ }^{6}$

The best radiological tool to recognize hydrocephalus in children is via the VHR (normal VHR is 24-33\%); any value above that is considered abnormal. ${ }^{13}$ The purpose of our study was to make a conclusion on whether the choice of shunt pressure low vs medium affects the outcome in the pediatric hydrocephalus group. Both of our groups were comparable in relation to the age of the patients. We have used Ultrasonography as an effective tool in diagnosing progressive ventricular dilatation in children with open fontanelle. ${ }^{14}$ Patients with fused fontanelle and patients with congenital hydrocephalus underwent a CT scan or magnetic resonance imaging head for objective assessment of the VHR and a proper evaluation of the intracranial pathology causing hydrocephalus. Beside symptomatic improvement, both groups show a significant decrease in VHR in follow-up, but there is statistically no difference in the change in ratio in comparing both groups. It was expected that low-pressure shunts would have better resolution of ventricular dilatation and a higher incidence of slit ventricle syndrome as compared with the medium-pressure shunts. ${ }^{1}$ However, in our study, the resolution of ventricular system dilatation showed no difference in either group. Shunts' outcome was also assessed on the basis of complications and the need for redo surgery. On average, each patient of hydrocephalus is likely to have two to three operations throughout their life for shunt revisions; about $40-60 \%$ of shunt develops complication at some stage. One-third of these complications occur within the first year of shunt placement. ${ }^{15-16}$ The total complication in our study was $20 \%$, which compares favorably with the results in the literature partly due to a lower incidence of postmeningitis hydrocephalus in our study. The group-wise complication rates in groups A and B were $21 \%$ and $19 \%$, respectively. The incidence of shunt blockage was found in $10 \%$ of the total cases, two in each group. However, shunt breakage was found only in one case of group B. Shunt infection was found in two cases of group $A$ and in one case in group $B$.

\section{CONCLUSION}

This study demonstrated no statistically significant difference in the outcome when either low-pressure or medium-pressure shunts are used in pediatric hydrocephalus. The degree of resolution of dilated ventricles was also found to be independent of shunt opening pressure. There was no difference in complication rates with either shunt type.

\section{REFERENCES}

1. Grover S, Menon P, Samujh R, Rao KL. Congenital hydrocephalus: A comparative study on the efficacy and complications after low versus medium pressure ventriculoperitoneal shunts. J Indian Assoc Pediatr Surg. 2004; 9: 143-7.

2. Pollack IF, Albright AL, Adelson PD. A randomized controlled study of a programmable shunt valve versus a conventional valve for patients with hydrocephalus. Hakim-Medos Investigator group. J Neurosurg. 1999; 45: 1399-408.

3. Drake JM, Kestle JR, Milner R, John MR, Joseph $P$, Haines $S$, et al. Randomized trial of CSF shunt valves design in paediatric hydrocephalus. Neurosurgery, 1998; 43: 294-305.

4. Drake JM, Kestle JR, Bilting C, John MR, Haines S, Joseph P. Evolution of CSF shunt valves design in paediatric hydrocephalus. Neurosurgery, 1989; 32: 191-5.

5. Boon AJ, Trans JT, Delwel EJ. Dutch normal 
pressure hydrocephalus study: Randomized comparison of low and medium pressure shunts. J Neurosurg. 1998; 88: 490-5.

6. Robinson S, Kaufman BA, Park TS. Outcome analysis of initial neonatal shunts: Does the valve makes a difference? J Paediatr Neurosurg. 2002; 37: 287-94.

7. Mc Quarrie IG, Schrer PB. Treatment of adult onset obstructive hydrocephalus with low or medium pressure CSF shunts. Neurology, 1982; 32: 105761.

8. Michael $S$, Turner MD. The treatment of hydrocephalus: A brief guide to shunt selection. Surg Neurol. 1995; 43: 314-23.

9. Larsson A, Jenson C, Bliting $M$, Ekohlm $S$, Stephensen $\mathrm{H}$. Does the shunt opening pressure influence the affect of shunt surgery in normal pressure hydrocephalus. Acta Neurochir (Wien), 1992; 117: 15-22.

10. Sainte-Rose C, Piatt J, Jr, Renier D, Pierre-Kahn A, Hirsch JF, Hoffman $\mathrm{HJ}$, et al. Mechanical complications in shunts. Pediatr Neurosurg. 1991; 17: 2-9.

11. Matson D, Becker DP, Nulsen FE. Control of Hydrocephalus by valve-regulated venous shunt: Avoidance of complications in prolonged shunt maintenance. J Neurosurg. 1968; 28: 376-8.

12. Warf BC. Comparison of 1-year outcome for the Chhabra and Codman-Hakim micro precision shunt systems in Uganda: A prospective study in 195 children. J Neurosurg. 2005; 102 (Suppl. 4): S358-62.

13. Appareti KE, Johnson ML. Ultrasound evaluation of neonatal brain. In: Hagen-Ansert SL, editor. Textbook of diagnostic ultrasonography. USA: C.V. Mosby, 1983: pp. 270-84.

14. Boon AJ, Tans JT, Delwel EJ, Egeler-Peerdeman SM, Hanlo PW, Wurzer HA, et al. Dutch NormalPressure Hydrocephalus Study: Randomized comparison of low and medium pressure shunts. J Neurosurg. 1998; 88: 490-5.

\section{Additional Information}

Disclosures: Authors report no conflict of interest.

Ethical Review Board Approval: The study was conformed to the ethical review board requirements.

Human Subjects: Consent was obtained by all patients/participants in this study.

\section{Conflicts of Interest:}

In compliance with the ICMJE uniform disclosure form, all authors declare the following:

Financial Relationships: All authors have declared that they have no financial relationships at present or within the previous three years with any organizations that might have an interest in the submitted work.

Other Relationships: All authors have declared that there are no other relationships or activities that could appear to have influenced the submitted work.

\section{AUTHORS CONTRIBUTIONS}

\begin{tabular}{|l|l|l|}
\hline Sr.\# & Author's Full Name & Intellectual Contribution to Paper in Terms of: \\
\hline 1. & Mian Awais & Study design and methodology. \\
\hline 2. & Akhtar Munir & Paper writing, referencing, and data calculations. \\
\hline 3. & Laeeq-ur-Rehman & Data collection and calculations. \\
\hline 4. & Akmal Hussain & Analysis of data and interpretation of results etc. \\
\hline 5. & Ihsan Ullah & Literature review and manuscript writing. \\
\hline 6. & Lubna ljaz & Analysis of data and quality insurer. \\
\hline
\end{tabular}

